\title{
Documentalismo fotográfico y conflictividad sociolaboral. Análisis del caso de la huelga general de 2010 en los diarios españoles
}

\author{
Joaquín LÓPEZ DEL RAMO \\ Universidad Rey Juan Carlos \\ joaquin.lopezdelramo@urjc.es \\ Juan-Francisco TORREGROSA \\ Universidad Rey Juan Carlos \\ juanfrancisco.torregrosa@urjc.es
}

Recibido: 05/02/2011

Aceptado: 10/03/2011

\section{RESUMEN}

Investigación de los rasgos denotativos y connotativos de las fotografías sobre la huelga general de 29 de septiembre de 2010 en los diarios La Vanguardia, El País, El Mundo, Abc y La Razón. Se utiliza una ficha de análisis de diseño original para registrar las variables más significativas. Se constata un amplio y variado grado de cobertura del conflicto y una elevada visibilidad de las fotos. La huelga no aparece como un hecho masivo, hay un alto componente de tensión y los gestos de los personajes no responden completamente al estereotipo tópico. Las principales diferencias entre los diarios se centran en el número de fotos publicadas, la omisión de escenas y tipos de personajes y la gestualidad que muestran los protagonistas.

Palabras clave: Documentalismo fotográfico; fotoperiodismo; huelga general; La Vanguardia; El País; El Mundo; Abc; La Razón.

Photographic documentalism and sociolabour conflict. Research work on the general strike of 2010 in the Spanish newspapers.

\begin{abstract}
Research work of the denotative and connotative features of the photographs about the general strike on September $29^{\text {th }} 2010$ in the newspapers La Vanguardia, El País, El Mundo, Abc and La Razón. An analysis card of original design is used to register the most important variables. The results reflects a wide and varied degree of coverage of the conflict and a high visibility of the photos. The conflict does not appear as a massive fact and there is a high component of tension and the gestures of the characters answer to the hackneyed stereotype. The main differences between the newspapers are focussed on the number of published photos, the omission of scenes and types of prominent figures and the gestures that the protagonist show.
\end{abstract}

Key words: Photographic documentalism; photojournalism; general strike; La Vanguardia; El País; El Mundo; Abc; La Razón. 


\section{INTRODUCCIÓN}

El presente trabajo plantea la aproximación empírica a un hecho noticioso concreto, como es el tratamiento fotográfico de la huelga general del 29 septiembre de 2010 en la prensa de referencia en España. El propósito esencial es determinar y describir los elementos de significado informativo que aportan las imágenes y, en consecuencia, la visión que los diarios transmiten del evento.

La importancia periodística del área socio-laboral y, más concretamente, de las huelgas, ha sido puesta de manifiesto por expertos en información especializada como Esteve-Ramírez y Fernández-del-Moral, quienes afirman (1999, p. 234) que los medios dan prioridad de tratamiento a los hechos que comportan algún grado de conflictividad. Coca $(2004$, p. 321) incide en la misma idea al considerar que los conflictos son la parte de este área de especialización periodística "más fotogénica, por ser en general la única que aporta imágenes vivas y de movimiento, y la que tiene incidencia mayor en los ciudadanos".

Dada la prevalencia de la información visual sobre la literaria, hay en el receptor una visión estereotipada de algunos acontecimientos relevantes, que la reiteración de imágenes similares ha fijado en el subconsciente colectivo a modo de "fotogramas" asociados en forma tópica con el evento y sus actores. En el estereotipo visual de las huelgas domina la tensión y los personajes juegan un rol preestablecido: dureza policial, reivindicación y protesta sindical, disgusto de los políticos afectados y, en su caso, de los empresarios, serían algunos de los patrones habituales.

Al final hablamos de imágenes que son fruto de la forma en que el fotógrafo captura la realidad a través de una serie de códigos de selección y procesamiento (angulación, encuadre, etc.) en los que se encuentra su interpretación personal, la parte más connotativa-subjetiva. En tal sentido y siguiendo a Sánchez-Vigil (2006, p. 151): "La fotografías sugieren. La lectura personal de las imágenes despierta la conciencia y el lector encuentra en cada detalle el punto de partida para crear una historia, plasmar sentimientos o criticar los hechos".

Precisamente esta investigación considera la composición y la lectura de las fotografias, a partir de nociones esenciales como las de denotación y connotación, en la línea planteada por Marcos-Recio (2008, p. 91): “¿Qué dice esa imagen? ¿Qué mensaje contiene? Para ello, se tiene en cuenta que creador/artista y receptor/público están utilizando los mismos códigos. Y en segundo lugar, lo que hay más allá de ese mensaje, lo que no está de manera explícita en la imagen. En definitiva, denotación y connotación si se siguen los paradigmas clásicos de la imagen".

$\mathrm{Si}$ el documentalismo fotográfico y el fotoperiodismo cuentan con un nutrido corpus de referencias teórico-conceptuales, la difusión de estudios de fotografía sobre hechos concretos de interés informativo es bastante reducida. Entre los más relevantes está "La imagen de la OTAN a través de la prensa española", dirigido por Vilches (1987, pp.125-280). Otros son los de López-del-Ramo (2008, pp. 177-183), que examina la imagen fotoperiodística de los líderes políticos en campaña electoral, y Cuvardic (2004) relativo a la construcción y representación fotográfica de los conflictos sociopolíticos. 
La propuesta que aquí se presenta pretende realizar una nueva aportación en esta misma línea, y parte para ello de tres hipótesis fundamentales:

- Dada la importancia económica, social y política de una huelga general, se presume una amplia y exhaustiva cobertura gráfica por parte de los periódicos.

- Las fotografías sobre huelga general pueden presentar una imagen previsible o estereotipada, sobre todo en lo referido a los papeles que desempeñan los diferentes actantes.

- La visión del conflicto y de sus principales protagonistas puede estar sesgada por la afinidad ideológica de cada una de las cabeceras.

Los objetivos de la investigación son los siguientes:

1. Determinar la importancia cuantitativa de la cobertura fotográfica de la huelga general realizada por los diarios, como reflejo del interés informativo que le otorgan.

2. Establecer cuál es la visión general del acontecimiento: si se muestra una participación masiva o no, una tensión elevada y si hay omisiones relevantes.

3. Examinar los rasgos gestuales y de actitud que muestran los principales protagonistas de la huelga y confrontarlos con su estereotipo iconográfico.

4. Comparar el tratamiento de los factores anteriores en los cinco diarios objeto de análisis en aquellos aspectos donde se producen discordancias.

\section{METODOLOGÍA}

La investigación se llevó a cabo sobre los cuatro diarios españoles de tirada nacional con mayor difusión, según las cifras de la OJD correspondientes a 2010: Abc, La Razón, El Mundo y El País, además del diario La Vanguardia, por su liderazgo entre las cabeceras de prensa regionales. Al tratarse de un acontecimiento limitado a la jornada de la propia huelga general, el objeto de estudio fueron las ediciones correspondientes al día siguiente, 30 de septiembre de 2010, siendo examinadas la totalidad de fotografías relacionadas con este asunto, con independencia de la sección donde aparecieran. Con estos límites, la muestra se compuso de 158 imágenes, cada una de las cuales se definió como unidad de análisis.

En cuanto al diseño y procedimiento, el método básico empleado fue una ficha de diseño propio concebida con un criterio de adecuación a las singularidades de las fotografías a examinar y a los fines del trabajo. Para su elaboración se tomaron como base los esquemas sobre análisis documental y de contenido de la fotografía de prensa elaborados por Félix del-Valle (1999), Vilches (1987) y particularmente AlonsoErausquin (1995), de los cuales el presente artículo adopta buena parte de sus fundamentos teórico-conceptuales.

La ficha queda configurada de la siguiente manera: 


\begin{tabular}{|l|l|}
\hline 1. Atributos denotativos & Descripción \\
\hline Indicador & $\begin{array}{l}\text { La Vanguardia, Abc, El Mundo, El País o La } \\
\text { Razón }\end{array}$ \\
\hline 1.1. Periódico & Portada, página par o impar \\
\hline 1.2. Página de publicación & Ancho medido en columnas de la pauta del diario \\
\hline 1.3. Tamaño & $\begin{array}{l}\text { Sujetos u objetos presentes en la imagen y papel } \\
\text { que desempenan }\end{array}$ \\
\hline 1.4. Actantes y roles & Localidad de obtención de la imagen \\
\hline 1.5. Lugar & $\begin{array}{l}\text { Catalogación de la imagen respecto al episodio } \\
\text { específico del acontecimiento }\end{array}$ \\
\hline 1.6. Episodio & $\begin{array}{l}\text { Si la imagen aporta información y la refuerza o es } \\
\text { sólo decorativa }\end{array}$ \\
\hline 1.7. Aportación al contenido
\end{tabular}

\begin{tabular}{|l|l|}
\hline 2.Atributos connotativos & Descripción \\
\hline Indicador & Campo de visión captado: general, grupal o corto \\
\hline 2.1. Encuadre & $\begin{array}{l}\text { Gestualidad que muestran los actantes en la } \\
\text { imagen, tanto en el rostro como en su expresión } \\
\text { corporal. }\end{array}$ \\
\hline 2.2. Impresión gestual & $\begin{array}{l}\text { Tipo de ambientación general que se desprende de } \\
\text { los rasgos escenográficos y gestuales. }\end{array}$ \\
\hline 2.4. Elementos simbólicos & $\begin{array}{l}\text { Presencia de gestos o elementos que posean una } \\
\text { componente simbólica significativa respecto al } \\
\text { hecho. }\end{array}$ \\
\hline
\end{tabular}

\section{Resultados}

\section{$\underline{\text { Indicadores denotativos }}$}

\section{Número de fotos}

El total de fotografías de la muestra se compone de 158 unidades, de las cuales la mayor parte se publican en al diario Abc, seguido por este orden de El Mundo, La Razón, la Vanguardia y El País. Llama la atención la diferencia entre el número de fotos de los tres primeros periódicos y los dos últimos, desequilibrio que se cifra en una proporción aproximada de 3 a 1 . 


\begin{tabular}{|l|l|l|}
\hline & $\mathbf{N}^{\mathbf{0}}$ Fotos & $\begin{array}{l}\text { Porcentaje } \\
\text { sobre el total }\end{array}$ \\
\hline La Vanguardia & 14 & $8,9 \%$ \\
\hline El País & 12 & $7,6 \%$ \\
\hline El Mundo & 42 & $26,6 \%$ \\
\hline Abc & 50 & $31,6 \%$ \\
\hline La Razón & 40 & $25,3 \%$ \\
\hline TOTAL & 158 & $100 \%$ \\
\hline
\end{tabular}

Tabla 1I: Número de fotografias sobre el acontecimiento

\section{Páginas}

La mayor parte de las fotografías van en página par, aunque la diferencia con respecto a las que aparecen en la impar no es muy considerable. Esta es una orientación general, salvo en el diario La Vanguardia. Es significativo que en todos los periódicos examinados se publicó alguna fotografía de la huelga en portada.

\begin{tabular}{|l|l|l|l|}
\hline & Portada & Par & Impar \\
\hline La Vanguardia & $1(7,2 \%)$ & $5(35,7 \%)$ & $8(57,2 \%)$ \\
\hline El País & $2(16,6 \%)$ & $6(50 \%)$ & $4(33,3 \%)$ \\
\hline El Mundo & $2(4,7 \%)$ & $25(59,5 \%)$ & $15(35,7 \%)$ \\
\hline Abc & $1(2 \%)$ & $33(66 \%)$ & $16(32 \%)$ \\
\hline La Razón & $2(5 \%)$ & $20(50 \%)$ & $18(45 \%)$ \\
\hline MEDIA TOTAL & $8(5,1 \%)$ & $89(56,3 \%)$ & $61(38,6 \%)$ \\
\hline
\end{tabular}

Tabla 2: Páginas en las que se publican las fotografias. Se especifica frecuencia y porcentaje respecto al total de fotos publicadas por cada periódico.

\section{Tamaño de las fotos}

Predominan las fotos cuya anchura es de un tercio de la pauta, si bien, sumados los porcentajes de las fotos cuyo tamaño oscila entre toda página y media, el porcentaje se aproxima mucho al anterior. Las fotos-miniatura (menos de 1/3 del ancho de la pauta) son muy pocas. Por diarios, El País es el que publica las fotografías a mayor tamaño, mientras que Abc destaca en el extremo contrario. 


\begin{tabular}{|l|l|l|l|l|}
\hline & Toda página & $\mathbf{3 / 4}$ a 1/2 & $\mathbf{1 / 3}$ & Miniaturas \\
\hline La Vanguardia & $2(14,3 \%)$ & $4(28,6 \%)$ & $8(57,1 \%)$ & 0 \\
\hline El País & $5(41,6 \%)$ & $6(50 \%)$ & $1(8,4 \%)$ & 0 \\
\hline El Mundo & $6(14,2 \%)$ & $18(42,8 \%)$ & $18(42.8 \%)$ & 0 \\
\hline Abc & $3(6 \%)$ & $5(10 \%)$ & $36(72 \%)$ & $6(12 \%)$ \\
\hline La Razón & $7(17,5 \%)$ & $8(20 \%)$ & $22(55 \%)$ & $3(7,5 \%)$ \\
\hline MEDIA TOTAL & $23(14,6 \%)$ & $41(25,9 \%)$ & $85(53,8 \%)$ & $9(5,7 \%)$ \\
\hline
\end{tabular}

Tabla 3: Tamaño de las fotografias expresado en columnas de la pauta. Se especifica frecuencia y porcentaje respecto al total de fotos publicadas por cada periódico.

\section{Tipos de actantes}

Partiendo de que en una misma foto puede haber actantes de diferentes tipos, los sindicalistas son el grupo mayoritario, seguidos en orden decreciente de los trabajadores y usuarios de servicios, los cuerpos policiales y los políticos, y por detrás otros tipos de actantes, entre los cuales los empresarios son los de menor presencia. Por diarios, hay una orientación general similar, aunque se aprecian matices específicos que se explican posteriormente.

Los roles que desempeñan estos personajes son los tradicionales de las huelgas. Así, entre los sindicalistas predominan los piquetes, entre la policía los antidisturbios y entre los políticos los miembros del Gobierno y de su partido. Los únicos líderes sindicales que figuran son los secretarios generales de UGT y CCOO.

Es conveniente por su significación resaltar dos aspectos:

- Actantes presentes en todos los medios:

- Sindicalistas, líderes sindicales, políticos y activistas radicales.

- Actantes ausentes por medios:

- Trabajadores (El País)

- Transeúntes y espectadores (La Vanguardia y El País)

- Cuerpos de policía (La Vanguardia).

- Seguridad privada (El País, La Vanguardia, La Razón)

- Artistas (El País, La Vanguardia, La Razón)

- Empresarios (El País, La Vanguardia, La Razón, El Mundo) 


\begin{tabular}{|c|c|c|c|c|c|c|c|c|c|c|c|}
\hline & \multicolumn{11}{|c|}{ Actantes (*) } \\
\hline & 1 & 2 & 3 & 4 & 5 & 6 & 7 & 8 & 9 & 10 & 11 \\
\hline $\begin{array}{l}\text { La } \\
\text { Vanguardia }\end{array}$ & $42,8 \%$ & $7,1 \%$ & $35,7 \%$ & $7,1 \%$ & - & $21,4 \%$ & $14,2 \%$ & - & $7,1 \%$ & - & - \\
\hline El País & $41,6 \%$ & $25 \%$ & - & - & $33,3 \%$ & $8,3 \%$ & - & - & $16,6 \%$ & - & - \\
\hline El Mundo & $52,3 \%$ & $4 ' 7 \%$ & $31 \%$ & $12 \%$ & $21,5 \%$ & $2,4 \%$ & $16,6 \%$ & $7,2 \%$ & $2,3 \%$ & $2,3 \%$ & - \\
\hline $\mathrm{Abc}$ & $38 \%$ & $8 \%$ & $26 \%$ & $4 \%$ & $22 \%$ & $18 \%$ & $8 \%$ & $2 \%$ & $4 \%$ & $2 \%$ & $2 \%$ \\
\hline La Razón & $30 \%$ & $15 \%$ & $20 \%$ & $22,5 \%$ & $12,5 \%$ & $20 \%$ & $12,5 \%$ & - & $2,5 \%$ & - & - \\
\hline $\begin{array}{l}\text { MEDIA } \\
\text { TOTAL }\end{array}$ & $40 ' 5 \%$ & $10,2 \%$ & $25,3 \%$ & $11 \%$ & $18,4 \%$ & $14 \%$ & $11,4 \%$ & $2,5 \%$ & $4,4 \%$ & $1,3 \%$ & $0,6 \%$ \\
\hline
\end{tabular}

(*) 1.Sindicalista 2. Líder sindical 3.Trabajador o usuario de servicios, 4.Transeúnte o espectador, 5. Cuerpos de Policía, 6. Político, 7. Objeto, 8. Seguridad privada, 9. Activistas, 10. Artistas, 11. Empresario.

Tabla 4: Categorías de actantes por periódico. Se especifica el porcentaje respecto al total de fotos publicadas por cada periódico y sobre el total de la muestra respectivamente.

\section{Lugares}

La mayor parte de las fotografías fueron obtenidas en Madrid (51,2\%), seguida de Barcelona (12,6\%), Valencia (2,5\%), Bilbao, Sevilla, Toledo y Asturias $(1,2 \%)$ y, finalmente, también hay fotografías de Zaragoza, Santiago, Córdoba, Málaga, Ávila, Santander, Tarragona, Lérida, Vigo, Bruselas (0,6\%). En el 20,2\% de las imágenes no se determina el lugar de obtención.

\section{Episodios}

Los cuatro episodios sobre los que más fotografías se publicaron fueron el bloqueo de actividades laborales, actos vandálicos, bloqueo de medios de transporte y declaraciones políticas. A bastante distancia le siguen otros hechos desarrollados alrededor del conflicto. También es digno de mención el porcentaje de fotografías que no puede adscribirse a un suceso concreto ( $16.5 \%$ del total)

Contemplados los resultados de este indicador por diarios, los que mayor número de hechos de la huelga ilustran con fotografías son El Mundo y Abc, mientras que en el extremo opuesto se sitúan El País y La Vanguardia, que omiten fotografías de 6 y 5 episodios respectivamente. 


\begin{tabular}{|c|c|c|c|c|c|c|c|c|c|c|c|c|}
\hline & \multicolumn{12}{|c|}{ Episodios (*) } \\
\hline & 1 & 2 & 3 & 4 & 5 & 6 & 7 & 8 & 9 & 10 & 11 & 12 \\
\hline $\begin{array}{l}\text { La } \\
\text { Vanguardia }\end{array}$ & - & - & $14,2 \%$ & - & $7,1 \%$ & - & $21,4 \%$ & - & $14,2 \%$ & $21,4 \%$ & - & $21,4 \%$ \\
\hline El País & - & - & $8,3 \%$ & - & - & $8,3 \%$ & $8,3 \%$ & $16,6 \%$ & $25 \%$ & $16,6 \%$ & - & $16,6 \%$ \\
\hline El Mundo & $26,1 \%$ & $9,5 \%$ & $21,4 \%$ & $2,3 \%$ & $4,7 \%$ & $4,7 \%$ & $2,4 \%$ & $4,7 \%$ & $11,9 \%$ & $7,2 \%$ & $4,7 \%$ & - \\
\hline $\mathrm{Abc}$ & $16 \%$ & $2 \%$ & $20 \%$ & $2 \%$ & $4 \%$ & - & $10 \%$ & $12 \%$ & $12 \%$ & $4 \%$ & $2 \%$ & $16 \%$ \\
\hline La Razón & $5 \%$ & - & $7,5 \%$ & - & $5 \%$ & - & $20 \%$ & $12,5 \%$ & $12,5 \%$ & $7,5 \%$ & - & $32,5 \%$ \\
\hline TOTAL & $13,2 \%$ & $3,2 \%$ & $15,8 \%$ & $1,3 \%$ & $4,5 \%$ & $2 \%$ & $11,3 \%$ & $5,7 \%$ & $13,3 \%$ & $8,3 \%$ & $2 \%$ & $16,5 \%$ \\
\hline $\begin{array}{l}(*) \text { 1. Bloque } \\
\text { 4. Bloqueo c } \\
\text { 7. Declaracio } \\
\text { 10. Manifest }\end{array}$ & $\begin{array}{l}\text { de trans } \\
\text { ntros púb } \\
\text { nes políti } \\
\text { ción fina }\end{array}$ & $\begin{array}{l}\text { ortes, } \\
\text { licos, } 5 \\
\text { as, } 8 . \mathrm{N} \\
11 . \mathrm{Se}\end{array}$ & $\begin{array}{l}\text { Bloque } \\
\text { Problem } \\
\text { anifestac } \\
\text { vicios } m\end{array}$ & $\begin{array}{l}\text { de mer } \\
\text { s de mo } \\
\text { ones y a } \\
\text { nimos, } 1\end{array}$ & $\begin{array}{l}\text { ados, } 3 \\
\text { ilidad, } \\
\text { ctos de } \\
\text { 2. Indef }\end{array}$ & $\begin{array}{l}\text { Bloque } \\
6 . \text { Decla } \\
\text { poyo, } 9 \\
\text { nido. }\end{array}$ & $\begin{array}{l}\text { de act } \\
\text { aciones } \\
\text { Vanda }\end{array}$ & $\begin{array}{l}\text { dades la } \\
\text { indicale } \\
\text { mo y al }\end{array}$ & $\begin{array}{l}\text { cales } \\
\text { ados c }\end{array}$ & Ilejeros & & \\
\hline
\end{tabular}

Tabla 5: Episodios de la huelga que ilustran las fotografias. Se especifica el porcentaje sobre el total de fotos publicadas en cada periódico y sobre el total de la muestra respectivamente.

\section{Aportación al contenido}

El 100\% de las fotos de El Mundo tienen un vínculo directo con los hechos descritos en las informaciones, mientras que en Abc 7 de las imágenes (14\%) son de archivo o simplemente decorativas, ya que no aportan nada al contenido. En La Razón hay 13 fotos decorativas (el 32\% de las publicadas en este diario), y 2 tanto en La Vanguardia $(14,2 \%)$ como en El País (16,6\%).

\section{$\underline{\text { Indicadores connotativos }}$}

\section{Encuadre}

La mayor parte de las imágenes son planos generales $(43,7 \%)$, pero a poca diferencia de las de plano corto $(43,1 \%)$, mientras que las de plano medio abarcan el $10,7 \%$ y hay muy pocos planos detalle. Así pues, en conjunto predominan las fotos con planos abiertos, siendo mayoría los generales en el diario El Mundo, y los cortos en El País. 


\begin{tabular}{|l|l|l|l|l|}
\hline & General & Grupal & Corto & Detalle \\
\hline $\begin{array}{l}\text { La } \\
\text { Vanguardia }\end{array}$ & $42,8 \%$ & $14,2 \%$ & $42,8 \%$ & - \\
\hline El País & $41,6 \%$ & - & $58{ }^{\prime} 3 \%$ & - \\
\hline El Mundo & $54,7 \%$ & $14,2 \%$ & $23,8 \%$ & $7,2 \%$ \\
\hline Abc & $42 \%$ & $16 \%$ & $42 \%$ & - \\
\hline La Razón & $35 \%$ & $2,5 \%$ & $60 \%$ & $2,5 \%$ \\
\hline TOTAL & $43,7 \%$ & $10,7 \%$ & $43,1 \%$ & $2,4 \%$ \\
\hline \multicolumn{5}{|l}{} \\
\hline
\end{tabular}

Tabla 6: Tipo de encuadre que presentan las fotografias por periódico. Se especifica el porcentaje sobre el total de fotos publicadas en cada periódico y sobre el total de la muestra respectivamente.

\section{Gestualidad}

La categoría gestual predominante (eje de ordenadas) es el neutro o indefinido, con una diferencia del triple respecto a la segunda, que es la agresividad, y a escasa distancia de ésta la firmeza, satisfacción, indiferencia y enfado. Por tipos de actantes (eje de abcisas), en la mayoría también predomina el gesto neutro o indefinido, salvo en los siguientes: líderes sindicales, en los que la gestualidad más frecuente es la satisfacción; cuerpos de policía, grupo en el que el gesto mayoritario es la firmeza; seguridad privada, actantes que en su mayor parte muestran un gesto indiferente; activistas, cuyo gesto más repetido es la agresividad, y artistas, cuya gestualidad se reparte por igual en varias categorías. 


\begin{tabular}{|c|c|c|c|c|c|c|c|c|c|c|c|c|}
\hline \multirow{2}{*}{$\begin{array}{l}\text { Códigos } \\
\text { gestuales }\end{array}$} & \multicolumn{11}{|c|}{ Actantes (*) } & \multirow[b]{2}{*}{ TOTAL } \\
\hline & 1 & 2 & 3 & 4 & 5 & 6 & 7 & 8 & 9 & 10 & 11 & \\
\hline Accidental & 1 & - & - & - & - & - & - & - & - & - & 1 & $1,2 \%$ \\
\hline Neutro & 14 & 5 & 23 & 10 & 5 & 6 & - & 1 & - & - & - & $40,5 \%$ \\
\hline Indiferencia & 1 & 1 & 7 & 3 & - & 2 & - & 2 & - & - & - & $10,7 \%$ \\
\hline Enfado & 7 & - & 2 & 2 & 3 & 1 & - & - & 1 & - & - & $10,1 \%$ \\
\hline Agresividad & 12 & - & - & - & 5 & - & - & 1 & 6 & - & - & $15,1 \%$ \\
\hline Sorpresa & - & - & 1 & 1 & - & 1 & - & - & - & - & - & 1,8 \\
\hline Firmeza & 2 & 2 & 1 & 1 & 13 & 1 & - & - & - & - & - & $12,6 \%$ \\
\hline Satisfacción & 5 & 10 & - & - & - & 1 & - & - & 1 & 1 & - & $11,4 \%$ \\
\hline Apelación & 8 & 1 & - & - & - & 3 & - & - & 1 & 1 & - & $8,8 \%$ \\
\hline Reivindicación & 11 & - & - & - & - & - & - & - & - & 1 & - & $7,6 \%$ \\
\hline Defensiva & 5 & - & - & - & - & - & - & - & 1 & - & - & $3,8 \%$ \\
\hline Ocultación & 1 & - & - & - & - & - & - & - & 1 & - & - & 1,2 \\
\hline Seriedad & - & - & - & - & - & 1 & - & - & - & - & - & 0,64 \\
\hline Cansancio & 1 & - & - & 1 & - & 3 & - & - & - & - & - & $1,8 \%$ \\
\hline \multicolumn{13}{|c|}{$\begin{array}{l}\text { (*) 1. Sindicalista, 2. Líder sindical 3.Trabajador, 4.Transeúnte o espectador, 5. Cuerpos de Policía, } 6 . \\
\text { Político, 7. Objeto, 8. Seguridad privada, 9. Activistas, 10. Artistas, actores, } \\
\text { 11. Empresarios }\end{array}$} \\
\hline
\end{tabular}

Tabla 7: Porcentajes totales de de rasgos gestuales y frecuencia por tipos de actantes

\section{Gestualidad de actantes por periódicos}

Por cada uno de los tipos de actantes presentes en las fotografías del periódico, se presentan en orden decreciente las categorías gestuales que registran:

La Vanguardia

- Sindicalistas: enfado y agresividad (33\%), neutro, satisfacción y actitud defensiva $\left(16^{\prime} 6 \%\right)$.

- Líderes sindicales: apelación (100\%).

- Trabajadores: gesto accidental (40\%), neutro, enfado y satisfacción (20\%)

- Políticos: apelación (100\%).

- Activistas: actitud defensiva (100\%).

El País

- Sindicalistas: gesto neutro (60\%), actitud defensiva (40\%), satisfacción (20\%).

- Líderes sindicales: sus rasgos gestuales son Satisfacción, el 66\%, y Neutro, el $33 \%$.

- Cuerpos de policía: firmeza y agresividad (50\%), enfado y gestualidad neutra $(25 \%)$. 
- Políticos: satisfacción (100\%).

- Activistas: agresividad (100\%).

El Mundo

- Sindicalistas: apelación y reivindicación (18\%), gestualidad neutra y agresividad $(13,6 \%)$.

- Líderes sindicales: gestualidad neutra (100\%).

- Trabajadores: gestualidad neutra (69\%), enfado (7,6\%).

- Transeúntes y espectadores: gestualidad neutra e indiferencia (50\%)

- Cuerpos de policía: gestualidad neutra $(33,3 \%)$, enfado $(22,2 \%)$, agresividad y firmeza (11\%).

- Políticos: apelación y seriedad (50\%).

- Seguridad privada: neutro, indiferencia y agresividad (33\%).

- Activistas: agresividad (100\%).

- Artistas: satisfacción y apelación (50\%).

$\mathrm{Abc}$

- Sindicalistas: reivindicación (42\%), apelación (26\%), agresividad, gesto neutro y cansancio $(10.5 \%)$ y satisfacción $(5,2 \%)$

- Líderes sindicales: gestualidad neutra y reivindicación (50\%).

- Trabajadores: gestualidad neutra $(53,8 \%)$, indiferencia $(30,7 \%)$, firmeza y cansancio $(7,6 \%)$.

- Transeúntes y espectadores: gestualidad neutra $(100 \%)$.

- Cuerpos de policía: firmeza $(63,6 \%)$, gesto neutro $(18,1 \%)$, agresividad y actitud defensiva $(9 \%)$

- Políticos: cansancio (33,3\%), gesto neutro, satisfacción y apelación $(22,2 \%)$, gesto accidental y reivindicación $(11,1 \%)$.

- Seguridad privada: indiferencia $(100 \%)$.

- Activistas: agresividad (100\%).

- Artistas: reivindicación $(100 \%)$

- Empresarios: neutro (100\%)

La Razón

- Sindicalistas: gesto neutro (41,6\%), enfado (25\%), agresividad $(16,6 \%)$, y por igual con el 8,3\% indiferencia, satisfacción, apelación y reivindicación.

- Líderes sindicales: satisfacción $(66,6 \%)$, firmeza $(33,3 \%)$, neutro e indiferencia $(16,6 \%)$.

- $\quad$ Trabajadores: neutro (75\%), indiferencia $(37,5 \%)$ y sorpresa $(12,5 \%)$

- Transeúntes y espectadores: neutro (55.5\%), indiferencia, enfado, sorpresa y firmeza $(11,1 \%)$

- Cuerpos de policía: firmeza (80\%) y agresividad (20\%).

- Políticos: neutro (50\%), indiferencia y sorpresa (25\%), enfado, firmeza y satisfacción $(12,5 \%)$

- Activistas: agresividad (100\%). 


\section{Ambientación}

Para la lectura correcta de los resultados debe tenerse en cuenta que algunas imágenes no muestran una ambientación definida por carecer de información sobre el entorno. Asimismo, es compatible la existencia de varios tipos de ambientación en una misma foto.

La categoría mayoritaria en el conjunto de la muestra es Tensión, seguida de Violencia y Realce masivo, y ya por debajo de éstas el resto de categorías. De los cinco diarios examinados, en tres de ellos (El Mundo, Abc y La Razón) predomina sobre las otras ambientaciones la Tensión, mientras que en El País es Violencia y en La Vanguardia es Realce masivo.

\begin{tabular}{|c|c|c|c|c|c|c|c|c|}
\hline & \multicolumn{8}{|c|}{ Categorías (*) } \\
\hline & 1 & 2 & 3 & 4 & 5 & 6 & 7 & 8 \\
\hline La Vanguardia & $28,5 \%$ & - & $14,2 \%$ & $21 \%$ & $7 \%$ & $14,2 \%$ & - & - \\
\hline El País & $17 \%$ & - & $17 \%$ & $15 \%$ & $18 \%$ & - & $8 \%$ & $8 \%$ \\
\hline El Mundo & $7,2 \%$ & $4,7 \%$ & $14,3 \%$ & $14,3 \%$ & $21.5 \%$ & - & $7,2 \%$ & $2,4 \%$ \\
\hline $\mathrm{Abc}$ & $6 \%$ & $2 \%$ & $2 \%$ & $14 \%$ & $22 \%$ & - & $12 \%$ & $2 \%$ \\
\hline La Razón & $15 \%$ & $7,5 \%$ & $7,5 \%$ & $10 \%$ & $20 \%$ & $2,5 \%$ & - & $7,5 \%$ \\
\hline TOTAL & $11,4 \%$ & $3,8 \%$ & 8,9 & $14 \%$ & $19 \%$ & $1,9 \%$ & $6,4 \%$ & $3,8 \%$ \\
\hline
\end{tabular}

(*) 1. Realce masivo, 2. Dispersión, 3. Ahogo/opresión, 4. Violencia, 5. Tensión, 6. Dramatismo, 7. Inactividad,

8. Festiva o alegre

Tabla 8. Ambientación predominante: porcentaje sobre el total de fotos publicadas en cada periódico y sobre el total de la muestra respectivamente.

\section{Simbolismo}

La mayor parte de las fotografías $(62,1 \%)$ no muestran rasgos o elementos simbólicos. Aquellas en las que sí aparecen, éstos son en su mayor parte logotipos de sindicatos $(14,5 \%)$ y el resto $(13,2 \%)$ son banderas, la mayoría de los diferentes sindicatos y varias de la $2^{\mathrm{a}}$ República, de Cataluña y de España. Únicamente el 1,2\% de las fotografías muestra gestos de connotación simbólica, como son personas con un puño en alto.

\section{CONCLUSIONES}

1. Los diarios otorgan en conjunto una elevada importancia informativa a la huelga. A ello apuntan factores como el considerable número de imágenes, su grado de visibilidad con presencia en todas las portadas y su tamaño destacado. La escasez de fotos de archivo, en beneficio de aquellas obtenidas en el lugar de los hechos, junto con 
la variedad de procedencias geográficas y la diversidad de episodios plasmados, evidencian una cobertura amplia.

2. No se da impresión de un conflicto multitudinario, sino más bien protagonizado por pequeños grupos, salvo la manifestación del final de la jornada. El predomino de los episodios de bloqueo de transportes y actividades laborales por parte de piquetes, así como las imágenes de actos vandálicos protagonizados por radicales transmiten una idea general de tensión.

3. La visión de la huelga es fundamentalmente dinámica, y gracias al tratamiento de los encuadres hay un equilibro entre información de la escenografía que envuelve los hechos y la proximidad a los personajes y sus reacciones. Los elementos simbólicos son previsibles.

4. Están presentes todos los actantes y roles característicos de las huelgas: piquetes, manifestantes y líderes sindicales, policía antidisturbios y políticos. Sin embargo, hay un significativo número de imágenes de trabajadores que no siguen la huelga o que llenan de forma masiva los medios de transporte para ir a su puesto laboral. Esta disociación entre trabajadores y sindicalistas puede operar como mensaje de fondo que transmite poco apoyo al conflicto.

5. La imagen de personajes más destacados está dentro del estereotipo convencional, pero con dos matices importantes: la policía muestra una imagen menos agresiva de lo que cabría presuponer y en el $25 \%$ de imágenes de sindicalistas éstos aparecen recriminando a trabajadores que no hacen huelga, actitud que, paradójicamente, no presentan ante la policía. Ello es aún más llamativo si se tiene en cuenta que en casi todas estas ocasiones trabajadores increpados se muestran pasivos o indiferentes.

6. El reducido número de fotos que se publican en La Vanguardia y El País en proporción a los otros diarios no queda suplido por su mayor tamaño (El País) o su publicación mayoritaria en página impar (La Vanguardia). Este factor cuantitativo empobrece el tratamiento gráfico de la huelga. En La Razón también se dan estas carencias, sobre todo debido a que se publican bastantes imágenes de archivo, inconexas respecto a los hechos reales.

7. Las omisiones de actantes y de episodios se centran sobre todo en El País, La Vanguardia y La Razón. Es revelador que en El País no se publique ninguna foto de trabajadores que no siguen la huelga y que se eludan imágenes sobre bloqueo de transportes y mercados o dificultades de movilidad. En las imágenes de La Vanguardia están ausentes los cuerpos de policía, tampoco aparecen algunos episodios de bloqueo y se da una visión más masiva de la huelga que en los otros diarios. La Razón elude, asimismo, episodios de bloqueo de mercados y centros públicos.

8. La imagen gestual de los personajes principales también varía de unos diarios a otros. En El País los sindicalistas aparecen con gestualidad neutra y poco o nada agresiva, al contrario que los cuerpos de policía, y los políticos transmiten satisfacción. En el resto de diarios, los sindicalistas sí muestran actitudes reivindicativas, increpantes e incluso agresivas, mientras que la policía mantiene su tradicional imagen de firmeza, pero no tan belicosa como en El País. 


\section{BIBLIOGRAFÍA CITADA}

ALONSO-ERAUSQUIN, Manuel. Fotoperiodismo: formas y códigos, Madrid: Síntesis, 1995. ISBN 84-773-8281-6

COCA, César. "La información laboral, una hermana pobre del periodismo". En: Fernández del Moral, Javier (coord.) Periodismo especializado. Barcelona: Ariel, 2004, pp. 317-331. ISBN 84-344-1302-7.

CUVARDIC-GARCÍA, Dorde. "Construcción y representación fotográfica de los conflictos sociopolíticos: la huelga de educadores del 2003 en el diario La Nación". Revista de Ciencias Sociales. Volumen 4, número 106. Universidad de Costa Rica, San José, pp. 93-106.

http://redalyc.uaemex.mx/redalyc/pdf/153/15310608.pdf

DEL VALLE-GASTAMINZA, Félix del (coord.) Manual de documentación fotográfica. Madrid: Síntesis, 1999, pp. 133-167. ISBN 84-7738-689-7

ESTEVE-RAMÍREZ, Francisco y FERNÁNDEZ DEL MORAL, Javier. Áreas de especialización periodística. Madrid: Fragua, 1999. ISBN 84-7074-108-X

LÓPEZ DEL RAMO, Joaquín. "Imagen fotoperiodística de los líderes políticos en campaña electoral: encuadre, escenografía y gestualidad". En: Ibersid, 2008, pp. 177-183. ISSN 1888-0967

http://ibersid.eu/ojs/index.php/ibersid/article/view/2228/1989

MARCOS-RECIO, Juan-Carlos. "La fotografía en la publicidad: archivos, bancos de imágenes y centros de documentación en el siglo XXI". En: Pacheco Rueda, Marta (coord.) La publicidad en el contexto digital. Viejos retos y nuevas oportunidades. Comunicación Social, Sevilla, 2008, pp. 87-112.

ISBN 978-84-96082-71-7

SÁNCHEZ-VIGIL, Juan-Miguel. El documento fotográfico. Historia, usos, aplicaciones. Trea: Gijón, 2006. ISBN 9788497042239

VILCHES, Lorenzo. Teoría de la imagen periodística, Barcelona: Paidós, 1987. ISBN 84-7509-408-2 